\title{
The Relationship between Balanced Scorecard Evaluation Approach and Organizational Performance of Commercial Banks of Nepal
}

\author{
Dr. Dilip Parajuli, \\ Associate Professor, Bhaktapur Multiple Campus, Tribhuvan University, Nepal \\ Dr. Prakash Shrestha* \\ Lecturer, Nepal Commerce Campus, Tribhuvan University, Nepal \\ E-mail of the corresponding author: mrprakashshrestha@gmail.com
}

\begin{abstract}
The main underlying aim of this study is to examine the relationship between the four perspectives of the BSC evaluation approach and organizational performance. This is descriptive and analytical research. The questionnaire survey is used for collecting information. A total of 945 questionnaires were distributed among the managers of 27 commercial banks. A response rate of 56.40 percent was obtained from these banks including state-owned banks, private banks, and joint-venture banks. The empirical results show that the overall performance of the commercial banks is adequate and satisfactory in all four BSC perspectives. The results of correlation analysis have also revealed positive and significant relationships among all the four dimensions of BSC and organizational performance. Therefore, the application of the BSC evaluation approach is the most important for increasing the organizational performance of companies and businesses.
\end{abstract}

Keywords: Approach, Balanced scorecard, Evaluation, Organizational performance, Perspective

DOI: $10.7176 /$ RJFA/11-18-01

Publication date:September $30^{\text {th }} 2020$

\section{Introduction}

Intense competition always creates a hard time for the corporate world. Of course, this is a highly hard time for almost all kinds of companies all over the world and Nepalese companies are not an exception. Organizations are termed as profit-making machines. So, they need to work more on the strategic management system to maximization their profitability along with long-lasting success (Rafiq, Zhang, Yuan, Naz, and Maqbool, 2020). Enhancement in performance has become a key issue for the success of business organizations. For this, these organizations need to pay attention to the efficient performance management and measurement system that refer to formal, information-based routines and procedures that managers use to maintain or alter patterns in organization activities (Simons, 2000).

Balanced Scorecard (BSC) is the most commonly used performance management and strategic management system in today's business field. It utilizes key performance indicators and critical success factors to transform the mission and strategy of an organization into a balanced set of integrated performance measurements. Ho and Chan (2002) state that the performance measures provide a concise yet complete picture of the progress an organization is making towards its mission and objectives. After developing the concept of BSC in the early 1990's (Kaplan and Norton, 1992), it has become the most commonly used management approach for assessing companies' success. Using this tool is thought to improve organizational outcomes, innovation levels, and productivity (Dar \& Presley, 2000).

The primary emphasis on performance assessment issues is how the appraisal process looks for the right underlying measures. In the early phase of performance measurement, people tend to rely on especially accounting performance (Otley \& Alexander, 2000). Many scholars have concluded that financial measures are inadequate for performance evaluation. Hayes (1977) and Brownell (1982) reported that accounting information is less appropriate as a focal element in organizational control with the increasing exposure of the organization, or subunits of it, to the environment. In fact, as an alternative to conventional accounting standards, several businesses are adopting the "BSC" method with financial perspective and the non-financial measures that focus on at least three other perspectives such as customers, internal business processes, and learning and growth (Kaplan \& Norton 1992, 1996). Therefore, this study focuses on BSC perspectives and their association with the performance of commercial banks of Nepal.

\section{The Problem of the Study}

The development of the Nepalese banking industry shows its great contribution to the country and communities. After the liberalized policy of the government in the 1990s, there is significant growth in terms of quantity and quality in the banking sector (Shrestha, 2019). This industry is highly competitive among banks competing with 
each other and with other financial institutions as well (Shrestha, 2018). Intense competition, developments in new technology, global economy recession, stock market instability and rising interest rates have created tremendous trouble for bankers to offer superior performance and maintain their organizations (Shrestha \& Parajuli, 2020). The banking industry is not beyond globalization's impact. The key national and international group of actors of this industry has converted the sector more competitive and dynamic. The banking performance evaluation in our context has been based on mere financial indicators. Since traditional accounting/financial based measures are used as the indicators for assessing banking performance can express past economic gains of the banks and these measures are still of importance in the performance measurement. Apart from the financial measures for performance evaluation, the implementation of the other three subjective perspectives in banking performance assessment should be the main issue of Nepalese banks' performance evaluation. Thus, the basic issue of this research is to examine Nepalese banks' contemporary performance evaluation applying four perspectives of the BSC approach. Therefore, the statement of the question of this study is: "what is the performance of Nepalese commercial banks as per the approach of BSC evaluation?

\section{Objectives of the Study}

This research aims to examine organizational performance by applying the BSC evaluation approach with its multidimensional perspectives like financial and non-financial indicators. The main underlying aim is to examine the relationship between the four perspectives of the BSC evaluation approach and commercial bank performance.

\section{Research Hypothesis}

The BSC supplemented conventional financial measures with criteria that measure performance concerning three additional perspectives such as customer perspective; perspective on internal business processes; and perspective on learning and growth. Therefore, it allows companies to monitor financial results while monitoring progress in capacity building and acquiring intangible assets. They need such intangible assets for future growth at the same time (Kaplan \& Norton, 1996). Literature shows that the BSC evaluation approach is associated with increased organizational performance (Hoque \& James, 2000). It is also believed that the BSC evaluation approach in each perspective (financial, customer, internal business process, and learning \& growth) is positively associated with organizational performance. Based on this assumption, the four sets of research hypotheses have formulated as below:

H1: The learning \& growth perspectives of the BSC approach have a positive and significant relationship with organizational performance.

$\mathrm{H} 2$ : The internal business process perspectives of the BSC approach have a positive and significant relationship with organizational performance.

H3: The customer perspectives of the BSC approach have a positive and significant relationship with organizational performance.

H4: The financial perspectives of the BSC approach have a positive and significant relationship with organizational performance.

\section{The Research Framework of the Study}

Based on the above discussion a research framework has been developed for this study. The schematic diagram of the framework has been presented below. 


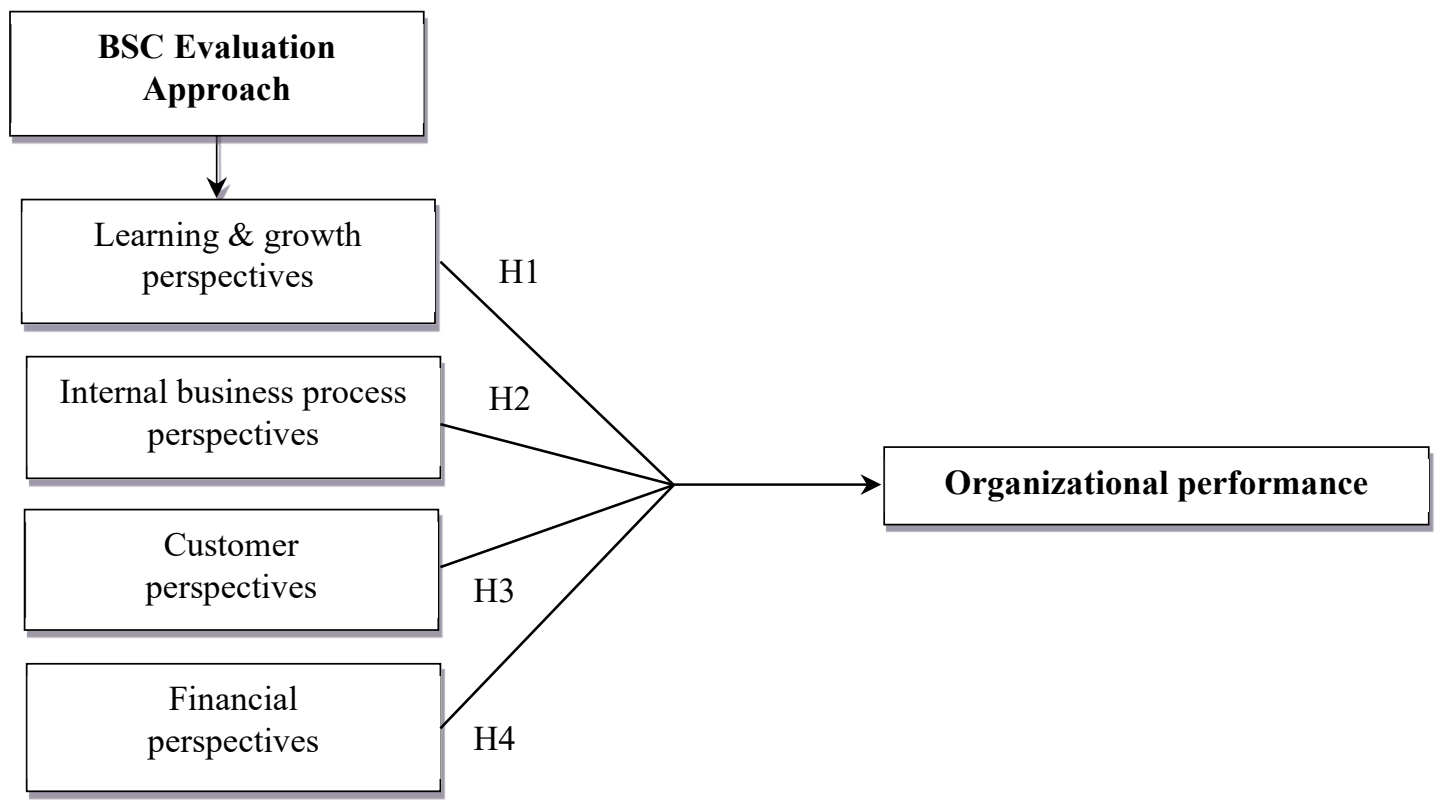

Figure 1: Research framework of the study

The four performance measurement perspectives of BSC are the independent variables in this study. These perspectives include learning \& growth perspective, internal business process perspective, customer perspective, and financial perspective. This study assumes the positive association between these performance measurement perspectives with the organizational performance of commercial banks of Nepal.

\section{Literature Review}

This section provides a literature review of key variables used in this study including BSC, its indicators or perspectives, and organizational performance.

\subsection{Balanced Scorecard (BSC)}

Kaplan and Norton (1992) reported that the BSC was initially considered as a performance measurement system that overcomes the systems' limitations that rely solely on the financial performance indicators. It adds three additional sets of non-financial performance indicators such as customer, internal process, and innovative \& learning to conventional financial indicators. Many studies (e.g. Chan \& Ho 2000; Hoque \& James 2000; Ittner \& Larcker 2003) reported that several companies have adopted the concept and incorporated it to enhance their operational efficiency, in both the private and public sectors.

Kaplan and Norton (1996) mentioned that the BSC translates mission and strategy into objectives and measures, organized into four different perspectives: financial, customer, internal business process, and learning $\&$ growth. They also add that the four perspectives of the scorecard permit a balance between short-and long-term objectives, between outcomes desired and the performance drivers of those outcomes, and between hard objective measures and softer, more subjective measures. They have proposed BSC as a new and complete performance measurement system that would aim at the goals of the corporate vision.

Many previous studies (Tabari \& Araste, 2008; Kaplan \& Norton, 1996; Hoque, 2014; Park \& Gagnon, 2006; Sundin, Granlund, \& Brown, 2010; Anand, Sahay, \& Saha, 2005; Ardabili, 2011) considered that BSC consists of four perspectives such as learning and growth, internal business process, customer, and financial perspective.

\section{Learning and Growth Perspective}

Learning and growth perspective is one of the key perspectives of the BSC evaluation approach that is concerned with the regulation of long-term institutional learning and development goals and criteria. It aims to provide the infrastructure needed to realize the high goals and improvements identified in other perspectives (Erdoğan, Onay, \& Karamaşa, 2019)

This perspective focuses on innovation, creativity, ability, and competency. This also focuses on people, their mindset, culture, experience, growth, etc. It also focuses on their capacity to learn and evolve for change and improvement management and sustainability. Besides, this approach also deals with workplace preparation and organizational cultural practices related to self-improvement, both personally and corporately (Narayanamma \& Lalitha, 2016).

In a knowledge-based company, people are the only repository of knowledge. So, they are assumed to be the major resources of the company. In the current days of rapid technological advancement, it is becoming essential 
for knowledge workers to involve in learning activities and be always in a continuous learning mode. Erdoğan, et al. (2019) further argue that the learning and growth perspective brings together both long-term innovation processes and short-term operational processes. The learning and growth perspective, thus, emphasizes on key variables like employee capabilities, employee satisfaction, training and development, employee morale, employee productivity, employee absenteeism, employee turnover, market share, new product share, technology, information technology, employee empowerment, teamwork, and culture and leadership.

\section{Internal Business Process Perspective}

This is the most critical perspective for the success of an organization. It includes internal business processes that ensure the highest quality of products and services. The managers should ensure that their businesses, based on internal processes, are running well and that the company's products and services are meeting the customers' requirements and creating value for them. This perspective helps the company to determine its competencies and the processes where it must excel to create customer delight. The internal perspective reflects the internal processes that should comply with the on-time attainment of goals, achieving short cycle times and resulting in high-quality internal processes. The objective of BSC for this particular perspective is to understand how to improve quality and reduce cycle time for the relevant internal processes (Sorensen, 2002). However, the key internal business process indicators for this study include service cycle duration, range of distribution reach, new products/services, training hours, customer needs identification, innovation process, operation process, post-sale services, and process delivery.

\section{Customer Perspective}

Niven (2005) argues that each organization must know: How do our customers see us? How should we appear to them? A large, satisfied customer base means more revenues that lead to improved financial outcomes. The customer perspective requires an organization to know how it should create value for its customers if it is to succeed (Pollanen \& Xi, 2018). Roya (2016) described the customer perspective as a recent trend of management philosophy wherein organizations are realizing the importance of customer satisfaction across various industries. Dissatisfied customers will find alternative sources to fulfill their needs, and this will result in business being lost for the organization (Roya, 2016). Panicker \& Seshadri (2013) also mentioned that customer satisfaction, customer complaints, the customer lost/won, and sales from a new product are the distinctive measure used under the customer perspective. However, the key customer perspectives indicators for this study include customer retention, customer profitability, customer acquisition, customer satisfaction, customer complaints, customer service times, market share, market penetration, service staff number, staff skills and competences, appearance and friendliness, number of new accounts opened, unique product, brand image, and social activities.

\section{Financial Perspective}

The BSC also gives equal importance to the financial perspective. It is assumed to be an important component of a strategy map of any kind of organization (Niven, 2011). Ardekani et al. (2013) argued that the financial perspective reflects the past operating performance of a company including the achievement of a financial target and the implementation of strategies. Despite this, it could be seen whether companies gain growth, return, and risk control from operating strategies. Financial perspective helps to answer the question on such a basis: How should we appear to shareholders? While today's companies rely on non-financial measures to deliver the bottom line score, the financial measures provide a common understanding for analyzing and comparing businesses. The key financial performance indicators for this study include operating income, product profitability, new customer and market, stakeholder relation, pricing strategy, new product and applications, operating cost, cost structure, assets utilization, revenue opportunities, productivity, and stakeholder value.

\subsection{Organizational Performance}

Performance measurement is seen as an effective way to keep a firm on track in achieving its goals and as a monitoring mechanism used by a company's owners where ownership and management are divided (Baker \& Wruck, 1989; Bushman, Indjejikian, \& Smith, 1995; Delaney \& Husekid, 1996; Huselid, 1995; Ittner \& Larcker, 1998; Kaplan, 1984; Lawler, Mohrman, \& Ledford, 1992; Mayo \& Brown, 1999). Organizational performance is a concept that is interconnected and signifies several indicators. To provide detail, several financial accounting measures are used. Some of the more popular measures prescribed by previous researchers (e.g. Gumbus \& Lyons, 2002; Ittner \& Larcker, 2003; Kalagnanam, 1997; Kaplan \& Norton, 1996) are earnings per share (EPS), cash flow, return on investment (ROI), return on assets (ROA), return on equity (ROE), return on capital employed (ROCE), price/earnings ratio, return on sales, asset turnover, and overhead/sales ratio. However, the key organizational performance indicators (both financial and non-financial) for this study include return on assets, return on equity, shareholders value, shareholders expectations, participative culture, commitment and loyalty, organizational citizenship, service quality, and teamwork.

\section{Research Methods}

This is descriptive and analytical research. The questionnaire survey is used for collecting information regarding 
the relationship of BSC perspectives and organizational performance of commercial banks of Nepal. There are 27 commercial banks in Nepal (https://bfr.nrb.org.np/bfrdirectives.php). Out of 27 banks, three are state-owned banks, five from joint-venture banks, and the remaining 19 private banks. The questionnaire was approached to managers (including corporate and senior managers, officers, and junior managers) of these commercial banks. A total of 945 questionnaires were distributed among these managers with an average of 35 questionnaires for each bank. A five-point Likert scale was used to measure the responses. The detail of the questionnaire distributed and their response rates are depicted in Table 1.

Table 1: Frequency of Questionnaire Responses

\begin{tabular}{lccc}
\hline Industry Type & No of questionnaires distributed & No of responses received & $\begin{array}{c}\text { Response rate } \\
\text { (In percent) }\end{array}$ \\
\hline State-owned banks & 105 & 80 & 76.20 \\
Private banks & 665 & 325 & 48.90 \\
Joint-venture banks & 175 & 128 & 73.10 \\
\hline \multicolumn{1}{c}{ Total } & 945 & 533 & 56.40 \\
\hline
\end{tabular}

As shown in the above table, a total response rate of 56.40 percent was achieved in this study. The highest response rate has been attained from the state bank group with 76.20 percent. The joint venture banking group provided 73.10 and the lowest response rate was from private banks with 48.90 percent that may be due to the lack of knowledge of the respondents about the BSC approach and the tendency of providing less importance to research issues. To analyze the data, descriptive statistics such as mean and standard deviation (S.D.) were used whereas the relationship between BSC evaluation approach and organizational performance was examined by using Pearson's correlation analysis.

\section{Empirical Results and Discussion}

This section presents the outcome of an empirical study.

\subsection{Descriptive Statistics}

The aggregate performance of each perspective of BSC and organizational performance are presented in Table 2.

Table 2: Descriptive Statistics of BSC Perspective

\begin{tabular}{clcc}
\hline S. no. & \multicolumn{1}{c}{ BSC perspective } & Mean & S.D. \\
\hline 1. & Learning \& growth perspective & 3.60 & 0.791 \\
2. & Internal business process perspective & 3.54 & 0.552 \\
3. & Customer perspective & 3.68 & 0.954 \\
4. & Financial perspective & 3.76 & 0.864 \\
5. & Organizational performance & 3.80 & 0.696 \\
\hline
\end{tabular}

\section{Note: $n=533$}

The result shows that the overall performance of the commercial banks is adequate and satisfactory in all four BSC perspectives. Among these perspectives, the financial perspective has the highest mean value of 3.76 (with S.D. of 0.864), which indicates a better financial position as perceived by the managers. Customer perspective has the mean value as 3.68 (with S.D. of 0.954 ) and it is the indication of better customer relation of the banks. The mean values of learning \& growth perspective and the internal business process are 3.60 (with S.D. of 0.791) and 3.54 (with S.D. of 0.552) respectively; the bank performance under these two dimensions also seems to be good. Similarly, the organizational performance as per manager's opinions is better as the aggregate mean value is 3.80 (with S.D. of 0.696). In this way, Nepalese commercial banks have better performance in all four perspectives of the BSC evaluation approach.

\subsection{The Relationship between the Balanced Scorecard Evaluation Approach and Organizational Performance}

To examine how four perspectives of the BSC evaluation approach are linked with the organizational performance of the banks, Pearson's correlation analysis has been applied. The results of the correlation are presented in Table 3.

Table 3: Correlation Results

\begin{tabular}{lccccc}
\hline BSC perspective & LGP & IBP & CP & FP & OP \\
\hline Learning and Growth Perspective (LGP) & 1 & $0.569^{* *}$ & $0.622^{* *}$ & $0.623^{* *}$ & $0.871^{* *}$ \\
Internal Business Perspective (IBP) & & 1 & $0.531^{* *}$ & $0.620^{* *}$ & $0.754^{* *}$ \\
Customer Perspective (CP) & & & 1 & $0.590^{* *}$ & $0.776^{* *}$ \\
Financial Perspective (FP) & & & & 1 & $0.686^{* *}$ \\
Organizational Performance (OP) & & & & 1 \\
\hline
\end{tabular}

Note: $n=533 ; * *$. Correlation is significant at the 0.01 level (2-tailed) 
The results show that the financial perspective of the BSC approach has a positive and significant correlation with the other three BSC perspectives including learning \& growth perspective, internal business perspective, and customer perspective. The results also show that all four BSC performance perspectives have a positive and significant association with organizational performance. The results strongly suggest that performance evaluation dimensions of the BSC approach are more consistent and correlated with the overall organizational performance of the commercial banks of Nepal.

\section{Hypotheses Testing}

This section deals with four sets of hypotheses formulated to explore Nepal's commercial banks' relationship between four viewpoints of the BSC assessment approach and organizational performance. Below are the results and discussions of the tests.

H1: The learning \& growth perspectives of the BSC approach have a positive and significant relationship with organizational performance.

The correlation coefficient between learning \& growth perspective and organizational performance is 0.871 and it is significant at 1 percent level of significance (i.e. $r=0.871, p<0.01$ ). As a result, this hypothesis test of the research is accepted (i.e. H1 is accepted). The result suggests that there is a positive and significant relationship between learning \& growth perspective and organizational performance of the commercial banks.

H2: The internal business process perspectives of the BSC approach have a positive and significant relationship with organizational performance.

The correlation coefficient between the internal business process perspective and organizational performance is 0.754 and it is significant at 1 percent level of significance (i.e. $r=0.754, p<0.01$ ). As a result, this hypothesis test of the research is accepted (i.e. H2 is also accepted). The result suggests that there is a positive and significant relationship between these two study variables.

H3: The customer perspectives of the BSC approach have a positive and significant relationship with organizational performance.

The coefficient of correlation between consumer perspective and organizational performance is 0.776 and is significant at the level of 1 percent (i.e. $r=0.776, p<0.01$ ). Consequently, this study hypothesis is accepted (i.e. H3 is accepted). The result suggests the relationship between these two study variables is positive and significant. H4: The financial perspectives of the BSC approach have a positive and significant relationship with organizational performance.

Since the correlation coefficient between financial perspective and organizational performance is 0.686 and it is significant at 1 percent level of significance (i.e. $r=0.686, p<0.01$ ). As a result, the last hypothesis test of the research is accepted (i.e. H4 is accepted). There is a positive and significant relationship between financial perspectives and organizational performance of commercial banks.

Table 4: Summary of Hypotheses Results

\begin{tabular}{|c|c|c|}
\hline \multicolumn{2}{|c|}{ Hypothesis } & Remark \\
\hline & $\begin{array}{l}\text { The learning \& growth perspectives of the BSC approach have a positive and significant } \\
\text { relationship with organizational performance. }\end{array}$ & Accepted \\
\hline $\mathrm{H} 2$ : & $\begin{array}{l}\text { The internal business process perspectives of the BSC approach have a positive and } \\
\text { significant relationship with organizational performance. }\end{array}$ & Accepted \\
\hline & $\begin{array}{l}\text { The customer perspectives of the BSC approach have a positive and significant } \\
\text { relationship with organizational performance. }\end{array}$ & Accepted \\
\hline & $\begin{array}{l}\text { The financial perspectives of the BSC approach have a positive and significant } \\
\text { relationship with organizational performance. }\end{array}$ & Accepted \\
\hline
\end{tabular}

\section{Conclusions}

This study was aimed at examining the performance of Nepalese commercial banks applying four of the financial and non-financial performance evaluation criteria under the BSC approach. From the analysis and results, it is found that Nepalese commercial banks pose satisfactory performance status more or less as per the BSC performance evaluation approach. Out of four BSC perspectives, Nepalese banks have relatively better performance from the financial perspective. Similarly, customer and learning \& growth are other perspectives of BSC having a better performance. However, the banks have relatively weak performance in the internal business process perspective.

Concerning the relationship between the BSC approach to evaluation and organizational performance, the facts show that there is a substantial positive relationship between all aspects of the BSC approach to evaluation and organizational performance. This suggests the more favorable approach to the evaluation of BSC, the more likely the successful and positive performance of the company. This means the successful use of the BSC method leads positively to the higher level of organizational efficiency or performance. Among them, learning \& growth perspective contributes more to organizational performance because the strength of the correlation is the highest 
between learning \& growth perspective and organizational performance. It is followed by the relationship between customer perspective and organizational performance, the relationship between internal business perspective and organizational performance, and the relationship between financial perspective and organizational performance.

To conclude, the empirical results of correlation analysis have shown positive and significant relationships among all the four dimensions of BSC and organizational performance. These results are the indications of the effectiveness of BSC as a performance measurement tool in evaluating organizational performance more holistically and comprehensively. The results of this study are consistent with the outcomes of many previous studies (e.g. Hoque \& James, 2000; Anand et al., 2005; and Purwohedi \& Dan, 2006). The findings of this study are also consistent with the results drawn some other previous studies (e.g. Tabari and Araste, 2008; Park \& Gagnon, 2006; Sundin et al., 2010; Ardabili, 2011; and Hoque, 2014), and Erdoğan, et al., 2019). All these studies concluded that the relationship between the BSC approach and the organizational performance is positive and significant. Therefore, these all suggest that the application of the BSC evaluation approach is the most important for increasing the organizational performance of our companies and businesses.

\section{Implications for Future Research}

As mentioned earlier, this study has attempted to reveal the performance of Nepalese commercial banks with a new perspective; the BSC approach. The performance of the banks has been appraised using both financial and non-financial measures including; financial perspective, customer perspective, internal process perspective, and learning \& growth perspective. This study is initial research in Nepal using the BSC approach for performance evaluation of the corporate sector. There is a possibility of further researches in this area. In this regard, future researches may apply more data sources to reveal a wider coverage of performance data within the BSC framework. Future research could be carried out in different industrial settings both service and manufacturing sectors. The present study has applied a questionnaire survey as the primary tool of data collection and future researches could be worked out applying other instruments of data collection. Similarly, future studies may conduct by using a time series analysis of organizational performance.

\section{References}

Anand, M., Sahay, B. S., \& Saha, S. (2005). Balanced scorecard in Indian companies. Vikalpa, 30(2), 11-25.

Ardabili, F. S. (2011). New framework for modeling performance evaluation for bank staff departments. Australian Journal of Basic and Applied Sciences, 5(10), 1037-1043.

Ardekani, S.S., Sharifabadi, A.M., Jalaly, M., \& Zarch, M.E. (2013). Comprehensive performance evaluation using FAHP-FVIKOR approach based on balanced scorecard (BSC): A case of Yazd's ceramic and tile industry. Iranian Journal of Management Studies, 3(4), 381-395.

Baker, G., \& Wruck, K. (1989). Organization changes and value creation in leverage buyouts: The case of the O. M. Scott \& Son Company. Journal of Financial Economics, 25(2), 160-195.

Brownell, P. (1982). A field study examination of budgetary participation and locus of control. The Accounting Review, 54(4), 766-777.

Bushman, R., Indjejikian, R., \& Smith, A. (1995). Aggregate performance measures in business unit manager compensation: the role of intra-firm interdependencies. Journal of Accounting Research, 33, 101-128.

Chan, Y.L.C, \& Ho., S.K. (2000). Performance measurement and the use of balanced scorecard in Canadian hospitals. Advances in Management Accounting, 9, 145 - 169.

Dar, H., \& Presley, J. (2000). Lack of profit loss sharing in Islamic banking: management and control imbalances. International Journal of Islamic Financial Service, 2(2), 3-18.

Delaney, J., \& Husekid, M. (1996). The impact of human resource management practices on perceptions of organizational performance. Academy of Management Journal, 39(4), 949-969.

Erdoğan, N.K., Onay, A., \& Karamaşa, C. (2019). Measuring the performance of retailer firms listed in BIST under the balanced scorecard perspective by using interval valued Pythagorean Fuzzy AHP based Pythagorean Fuzzy TODIM Methodology. The Journal of Operations Research, Statistics, Econometrics and Management Information Systems, 7(2), 333-350.

Gumbus, A., \& Lyons, B. (2002). The balanced scorecard at Philips electronics. Strategic Finance; Montvale, 84(5), 45-49.

Hayes, D. (1977). The contingency theory of management accounting. The Accounting Review, 52(1), 22-40.

Ho, S.K., \& Chan, Y.C.L. (2002). Performance measurement and implementation of the balanced scored card in municipal governments. The Journal of Government Financial Management, 51(4), 8-19.

Hoque, Z. (2014). 20 years of studies on the balanced scorecard: Trends, accomplishments, gaps and opportunities for future research. The British accounting review, 46(1), 33-59.

Hoque, Z., \& James, W. (2000). Linking balanced scorecard measures to size and market factors: impact on organizational performance. Journal of Management Accounting Research, 12, 1-17.

Huselid, M. (1995). The impact of human resource management practices on turnover, productivity, and corporate 
financial performance. Academy of Management Journal, 38(3), 635-672.

Ittner, C. D., \& D. F. Larker. (2003). Coming up short on nonfinancial performance measurement. Harvard Business Review, 1-9.

Ittner, C. D., \& Larcker, D. F. (1998). Innovations in performance measurement: Trends and research implications. Journal of Management Accounting Research, 10, 205-238.

Ittner, C. D., Larcker, D. F., \& Rajan, M. V. (1997). The choice of performance measures in annual bonus contracts. The Accounting Review, 72(2), 231-255.

Kalagnanam, S. S. (1997). The use of non-financial performance measures and their relationship to strategy. University of Wisconsin, Madison, Wisconsin.

Kaplan, R. S. (1984). The evolution of management accounting. The Accounting Review, 59(3), 390-418.

Kaplan, R. S., \& Norton, D. P. (1992). The balanced scorecard: Measures that drive performance. Harvard Business Review, 70(1), 71-79.

Kaplan, R. S., \& Norton, D. P. (1996). Translating strategy into action: The balanced scorecard. Harvard Business School Press.

Kaplan, R. S., \& Norton, D. P. (1996). Using the balanced scorecard as a strategic management system. Harvard Business Review, 74(1), 75-85.

Lawler, E. E., Mohrman, S. A., \& Ledford, G. (1992). Employee involvement and total quality management practice and results in Fortune 1000 companies. San Francisco Jossey Bass.

Mayo, M. C., \& Brown, G. S. (1999). A competitive business model. Ivey Business Journal, 63(3), 18-23.

Narayanamma, P.L., \& Lalitha, K. (2016). Balanced scorecard-the learning \& growth perspective. Aweshar Research Journal, 21(2), 59-66.

Niven, R.P. (2005). Balanced scorecard diagnostics: Maintaining maximum performance. John Wiley \& Sons.

Niven, R.P. (2011). Balanced scorecard: Step-by-step for government and nonprofit agencies. John Wiley \& Sons.

Otley, D., \& Alexander, F. (2000). Reliance on accounting performance measures: Dead end or new beginning? Accounting Organizations and Society, 25(4/5), 497-510.

Panicker, S., \& Seshadri, V. (2013). Devising a balanced scorecard to determine Standard Chartered Bank's Performance: A case study. International Journal of Business Research and Development, 2(2), 35-42.

Park, J. A., \& Gagnon, G. B. (2006). A causal relationship between the balanced scorecard perspectives. Journal of Human Resources in Hospitality \& Tourism, 5(2), 91-116.

Pollanen, R.M., \& Xi, K.K. (2018). The effects of using balanced scorecard measures in executive compensation on organizational performance. International Journal of Business, Accounting, \& Finance, 12(1), 1-16.

Purwohedi, U., \& Dan, I. G. (2006). Designing balanced scorecard weight on Syariah Bank branches through performance measurement. Simposium Nasional Akuntansi.

Rafiq, M., Zhang, X., Yuan, Y., Naz, S., \& Maqbool, S. (2020). Impact of a balanced scorecard as a strategic management system tool to improve sustainable development: Measuring the mediation of organizational performance through PLS-Smart. Sustainability, 12, 1-19.

Roya, R. (2016). Application of balanced scorecard (BSC) in evaluating the performance of health care providers. International Journal on Recent and Innovation Trends in Computing and Communication, 4(3), 322 - 327.

Shrestha, P. (2018). Service quality and customer satisfaction: Evidence of Nepalese banks. NCC Journal, 3(1), 121-133. https://doi.org/10.3126/nccj.v3i1.20254

Shrestha, P. (2019). Banking customer attitudes toward ATM service in Nepal. International Journal of Advances in Scientific Research and Engineering, 5(12), 88-93. https://doi.org/10.31695/IJASRE.2019.33652

Shrestha, P., \& Parajuli, D. (2020). Impact of merger and acquisition practice on job stress: Evidence from Nepal. European Journal of Business and Management, 12(24), 1-8. DOI: 10.7176/EJBM/12-24-01

Simons, R. (2000). Performance measurement and control systems for implementing strategy: text \& cases. Prentice-Hall, Upper swaddle River.

Sorensen, J. B. (2002). The strength of corporate culture and the reliability of firm performance. Administrative Science Quarterly, 47(1), 70-91.

Sundin, H., Granlund, M., \& Brown, D. A. (2010). Balancing multiple competing objectives with a balanced scorecard. European Accounting Review, 19(2), 203-246.

Tabari, M., \& Araste, F. (2008). The balanced scorecard approach to performance evaluation, Management Journal, 5(12), 12-20 